\title{
The Development of Computer Management Information System for the Test Criterion of Food Safety of Large-Scale Shopping Malls
}

\author{
Tong Jiang, Dong Xie, Guangjun Guo, Yan Zhang \\ Information School, Hunan University of Humanities, Science and Technology, Loudi, 417000, \\ China
}

Keywords: Food safety; Large-scale shopping mall; Management information system

\begin{abstract}
Recently, food safety incident takes place frequently. As the last link of the future food supply chain, large-scale shopping mall is especially important in the safety guarantee of food. Through establishing management information system for large-scale shopping malls, this study can help large-scale shopping malls to keep away from food safety risks. Experiment proves that food safety incidents can be effectively prevented from happening by management information system for large-scale shopping mall. In addition, the system has advantages of high efficiency, flexibility, usability and expansibility. This paper explores new approach for large-scale shopping malls to prevent food safety incident happening.
\end{abstract}

\section{Introduction}

Recently, the problem of food safety takes place frequently, which becomes the focus of the globe. After the nuclear leak accident happened in Japan, exceeding radioactive substances were detected in the food exported from Japan for several times. Enter hemorrhagic Escherichia Coli incident which happened in Germany brought disaster to the whole country; it caused the death of more than 30 people and more than 3000 people were infected [1]. In the plasticizer incident which happened in Taiwan, near 300 enterprises were involved in; 7000 kinds of food were removed off shelves; pharmaceutical industry and cosmetics industry were also affected. From "Sanlu Milk Powder Incident" to "Clenbuterol Incident" and from the time when food safety problem was written into Government Work Report to the time (June 1, 2015) when Food Safety Law began to be implemented, the whole society began to pay more and more attention to the problem of food safety. The importance of public food safety is shown prominently [2]. The Central Committee of CPC has attached great importance to the problem of food safety. Food safety can involve food production units, supervision department and circulation market [3]. As a service industry of tertiary industry, large-scale shopping mall is showing its more and more important market position. It directly establishes the trading platform between supply and consumption and becomes an indispensable service section in the daily life of people.

Following the arrival of information times, more and more large-scale shopping malls begin to use Management Information System (MIS for short) to manage shopping malls. MIS is a new subject which is unceasingly developing [4]. Following the progress of computer technology and communication technology, MIS is unceasingly updated. Now food safety management and control for the foods from around the world to the shopping malls is more and more strict. In the process of management, market management staff are facing more and more problems. Problems such as the food traceability, supply channels, the temperature control of the frozen food, consumer habits, goods position on the counters interact each other etc., are highlighted in large shopping malls. With developments of computer technology and applications, compute management systems are more and more applied to all aspects of life. Computer management of food counters in shopping mall provides a good way to solve these problems. And using management information systems to ensure food safety, also become an important direction of the development of large shopping malls in the future. Information is an extremely important resource in management [5]. The success of management depends on effective decisions; in addition, the degree of the correctness of decisions depends on the quality of information in large degree. Therefore, it is the primary problem of 
enterprises to effectively manage information. MIS is becoming more and more popular in the modern society with the emphases of management and information. Following the progress of the society and the promotion of people's material and cultural life, the development of commodities changes with each passing day[6]. In particular, extreme difficulties can be brought to manual management by the establishment, modification and maintenance of the standard database of commodities' safety signs and the confirmation on commodity safety made by fixed person. It is impossible for non-safe operating methods to guarantee the safe permission of commodities and it is more impossible to establish accountability system[7]. At present, the normalized operating management of the shopping malls in our country is being explored. Complex market changes and consumption modes have not formed their laws. The management software aiming at shopping malls is only limited to single and independent module; security permission software and tracing software for commodities are unavailable now[8]. Therefore, it is the only approach of perfecting shopping mall management and establishing commodities' security permission and tracing mechanism to use advanced management means and utilize scientific management methodComputer Management Information System for the Test Criterion of Food Safety of Shopping Malls.

\section{Materials and methods}

The purpose of the system is to control all the data involved in management. Standard database of commodities' safety signs shall be firstly established. In addition, when inputting the data of commodity storage, commodity safety permission can be automatically identified; manufacturers' safety signs can be automatically extended and corrected. It has the functions of precaution, filtering, analogy, warning for historical notorious records, reputation quality assessment etc.. In this way, standard database of commodities' safety signs can be timely modified and maintained with high efficiency; standard database of commodities' safety signs becomes the sole commodity safety reference standard in the whole system operation. The normalized management of the whole shopping mall with the goal of commodities' safe permission can be achieved.

The system only collects the original data of commodities for one time to avoid the error caused by repetitive operations and improve operating efficiency. The system builds itself upon the current situation of users, gradually normalizes the actual procedures and deepens management contents. Management contents can be infinitely expanded and deepened without certain order according to actual needs. The data shall be connected without any obstacle. On one hand, the system shall devote itself to achieving extensive self-defined design including the type, precision and size of self-defined data, data retrieval scheme, data operation mode, data association flow direction, derivation data structure, data association inquiry, the format of statistic table, data transfer [9], data filtering scheme, data operation, data inquiry and data adjustment right etc.. The whole self-defined process takes the measures of logic control, tracing tips and misoperation protection. The system offers menu and options for users to use; non-relevant operations and data can be isolated by the system. On the other hand, the system shall automatically complete all the logic procedures, logic calculations, logic conflation and normalized operation. At the same time, the high operating speed and the ability of high-capacity memory of computer are sufficiently utilized; a large amount of skills of fuzzy screening, fuzzy invoking and fuzzy control are introduced; clear non-memory code operation is comprehensively achieved. In this way, users will completely break away from the knowledge of computer language; encoded operation can be achieved.

In order to adapt to the management of different types of data and make it convenient for different users to convert data, the software system refers to the superiority of database manipulations (DBMS) such as server and firstly defines the structure and type of data and data retrieval scheme. System Delphi + SQL Server is applied to compile program file; finally, one operating file and several parameter files, control files, picture files, overlay files and basic database files are compiled and integrated. The system completely breaks away from any language environment and directly runs in operating system, which greatly promotes the operating speed. The system is a network software and user of stand-alone machine is not limited. The number of network terminals (the number of customers) is irrelevant to the system. 
In order to automatically complete logic operation, the system permits self-defined classification and processing on relevant management data. In this way, different data can be automatically processed and transferred to meet requirement of self-defined management procedure and nonnormalized special requirements. At the same time, through setting self-defined automatic voucher, account treatment, report form statistics and the self-defined transfer of data of the system can be completed.

The system settings have the functions of self-defined screen inquiry, report form statistics and print preview for all data to randomly interact. The complex process of program design required by different format of report form statistics and unceasing inquiry change is solved. The inquiry requirements of different users can be met including report form at the end of month, financial analysis, marketing analysis, market analysis and the association, comparison and limitation of the data in different data fields of the whole system[10].

The system has established normalized operating authorization and safety mechanism. It isolates the visits from the exterior of the system and non-authorized operations and inquiries. Data operations shall be independently completed or checked by others. All of operating traces shall be reserved to achieve the sole operating responsibility, meet the operating conditions without pen recording and meet the requirements of all-round data management.

According to modern MIS theory, the system breaks through the obsolete mode of transversely dividing structure in accordance with job functions. According to the relationship among information processing, information use and information management, the structure of the system is comprised of three functions of system settings, data manipulations and data management. Data share is achieved thoroughly and the repetitive data manipulations are avoided. In addition, it is coincident with the habits of users. The structure of the system is extremely simplified. At the same time, considering the universality and popularization of the system, we independently design software system and application development to make them have widespread popularization application value. The software system has catalogue with three grades and it can be divided into five operating modules: system settings, data input, data check, data inquiry and data management. That contains users' demands of information processing, information use and information management. Users can be divided into system managers and operators. System managers have the authorities of managing this system, ascertaining and changing management contents, management procedures and operating methods, specifying and relieving the operating rights of operators. Operators only have the rights of data input, data check and data inquiry which are specified by system managers.

\section{Results and discussion}

The system utilizes professional software, regards advanced management theory as its basis, combines the actual management situation in China and uses scientific program structure and designing skills. This system was actually tested in Carrefour supermarket of Qingdao. After 90 days of operation, the customer complaints rate on food safety problems decreased from 35 cases per 20000 purchase behaviors to 6 cases per 20000 purchases. The complaint rates decreased from 1.75 per thousand, 0.3 per thousand. The tests results showed that the application of the system reduced the incidence of food safety complaint risks greatly.

It can fill in the blanks of data management integration, self definition of management mode and management procedures and the associated processing of non-relevant data. Through test, the system mainly has the following characteristics:

Intelligentization and high efficiency. Self definition makes data be controlled by the system; corresponding work of calculation, transfer, filing and storage can be done automatically. Users do not need to interfere those work. The data can automatically flow into corresponding departments to be managed or inquired. As for the daily normalized logic operations, the system can automatically keep accounts, produce vouchers, complete settlement and transfer. Users only need to operate the original data for one time and the final result can be got. In this way, the occurrence rate of wrong behaviors can be lowest and high efficiency can be achieved in management. The system 
sufficiently utilizes the powerful memory of computer and high-speed logic calculation, automatically completes logic operation, norm limits and data derivation and completes nonprofessional operations. The system can define operating formats and work environment and achieve the connection between the system and habits of human. The functions of self-defined work procedures and self-defined management modes of the system make it have wide application range. Following the unceasing development of enterprise and unceasing deepening of enterprise management, users can unceasingly develop new applications according to the detailed situation of managements. At last, every field of the whole enterprise management can be involved. When work mode, management contents or the structure of the system have change, users do not need to program and computer knowledge is dispensable. The system settings can be altered through the function of self definition to complete the maintenance of the system. Likewise, data maintenance can be completed through self-defined filtering. Enterprise does not need to employ professional computer staffs and the maintenance work can be completed easily can conveniently.

Security mechanism: The system is integrated compiled program and the visits from the exterior of the system are isolated. In operating process, the means of progressive encryption and limitation is used. The people who are not specified are prohibited to log in the system. Operators can only work in their scope of authority. The system can automatically conserve all the operating traces and sole operating responsibility can be achieved.

\section{Conclusion}

In our country, large-scale shopping mall was a burgeoning industry which gradually developed from the 1990s. The laws and regulations matching shopping mall are gradually being perfected in our country. Comparing with the development history of shopping mall for near one hundred years in western advanced countries, the management operation of shopping mall in our country still has large distance. The normalized management and normalized operation of shopping mall are becoming the important link of safe food supply and healthy consumption of people. At the same time, the supervision on the performance and price of commodities, the promotion of commodity circulation, the decrease of operating cost, the guarantee of commodity safety and the strengthening of sale service are in urgent need of normalized management and normalized operation. The development of this system offers a good solution for the food safety field of large-scale shopping mall.

\section{Acknowledgements}

This work is supported by the Research Foundation of Education Committee of Hunan Province, China (15C0724), Science and Technology Planning Project of Loudi Municipal Government, Hun an Province, China (2015RW03), and the Construct Program of the Key Discipline "Computer App lication Technology” in Hunan Province, China.

\section{References}

[1] Guowei Wan, Weizhen Yu and Munsur Rahman Mohammad, 2014. A Study on Changes of Vegetables' Marketing Network and Effect on Farmers' Income in the Bogra District of Bangladesh. Advance Journal of Food Science and Technology, 6(4): 499-505.

[2] Jacxsens, L., Kussaga, J., Luning, P. A., Van der Spiegel, M., Devlieghere, F., \& Uyttendaele, M. (2009). A microbial assessment scheme to measure microbial performance of food safety management systems. International Journal of Food Microbiology, 134 (1), 113-125.

[3] XiaoFei Zhao, 2014. Research on Dynamic Impact of Monetary Supply on Agricultural Industry and Food Price. Advance Journal of Food Science and Technology, 6(10): 1178-1183. 
[4] Xingkai Cui, 2015. Design of Food Management Information System Based on Humancomputer Interaction. Advance Journal of Food Science and Technology, 8(9): 650-653.

[5] Gibbon, P., \& Riisgaard, L. (2014). A New System of Labour Management in African Large Scale Agriculture. Journal of Agrarian Change, 14(1), 94-128.

[6] Lee, D. L., Lee, W. C., Xu, J., \& Zheng, B. (2002). Data management in location-dependent information services: Challenges and issues. IEEE Pervasive computing, 3(3), 65-72.

[7] Beulens, A. J., Broens, D. F., Folstar, P., \& Hofstede, G. J. (2005). Food safety and transparency in food chains and networks Relationships and challenges. Food Control, 16(6), 481486.

[8] Zan, L. S., Zheng, T. C., SHEN, G. L., WANG, L. G., \& ZENG, X. H. (2006). Design and Development of Quality Traceability Information Management System and Safety of the Beef Production’s Entire Processes [J]. Scientia Agricultura Sinica, 10, 2083-2088.

[9] McMeekin, T. A., Baranyi, J., Bowman, J., Dalgaard, P., Kirk, M., Ross, T., et. al. (2006). Information systems in food safety management. International Journal of Food Microbiology, 112(3), 181-194.

[10] Stone, R. N., \& Grønhaug, K. (1993). Perceived risk: Further considerations for the marketing discipline. European Journal of marketing, 27(3), 39-50. 